\title{
Synthesis, Characterization and Fungicidal Effects of some Organoborates
}

Shaheen Akther ${ }^{1}$

Khanal DP ${ }^{2}$

Ullah $\mathrm{SS}^{3}$

\begin{abstract}
Synthesis of benzoyl borate, phthasloyl borate and oxyl borate was done and characterized by infra red, ultraviolet and mass spectra. All newly synthesized and characterized organoborates were tested for their antifungal activity against pencillium that spoilt mostly celluloid materials stored in museum. All synthesized organoborates are unstable in room temperature and quickly degraded on exposure to air. Benzoyl borate found to be most active antifungal compound of the series against penicillium. The fungicidal activity increases in hydrophobicity and electron withdrawing nature of the benzene ring substituents. These compounds may be good fungicidal for the conservation of celluloid materials lying in the museum.
\end{abstract}

Key words: Organoborates, Silver metaborate, Acyl chloride, spore, Antifungal.

\section{Introduction}

All organoborates are synthesized with the used of silver metaborate $\left(\mathrm{AgBO}_{2}\right)$ and boric acid [1] with organic halides such as 3,5, dinitrobenzoyl chloride and p-nitrobenzoyl chloride. Since the silver atom in $\mathrm{AgBO}_{2}$ in photo activated state the reaction with organic halides having a polarized halogen atom will readily takes place with the formation of silver halides. Steric effect is an important factor in determining the course of reactions well as the stability of the product. It is observed that acyl chloride reacts more readily than sterically hindered pyrollium chloride [2]. The reaction of silver metaborate with organic halides may be ascribed to an ionic mechanism. Indeed acyllium [3] ion have been recognized as possible intermediate in acid catalyzed etherification in Friedel- Crafts reactions through the universality of such mechanism in doubt and the ion is assumed to resonate between the below structures:

$\mathrm{R}-\mathrm{C} \equiv \mathrm{O}^{+} \quad \leftrightarrow \mathrm{R}-\mathrm{C}^{+} \equiv \mathrm{O}$

The presence of $\mathrm{CO}$ group polarizes the carbon halogen bond to great extent. Various anhydrous crystalline and vitreous borates were examined by the method of embedding in $\mathrm{KBr}$ as well as by nujol method [4]. Applying composition a borate [5] salt such as metaborate salt. pyroborate salt, tetraborate salt or mixture of an area susceptible to microbiologically influenced corrosion is successful to prevent it.

\footnotetext{
${ }^{1}$ Jahangirnagar University, savar, Dhaka, Bangladesh

${ }^{2}$ M. Pharm, Ph.D, Prof.and HOD, Pharmacy, Purbanchal University, Manmohan Memorial Institute of Health Sciences Nakhu, Lalitpur, Nepal (to whom all correspondence to be addressed (Email-drdpk@ hotmail.com).

${ }^{3}$ M.Sc, Ph.D, FRSC Prof, Jahangirnagar University, savar, Dhaka, Bangladesh
} 
Organoborates semicarbazone and thiosemicarbazone complexes [6] prepared by treating mixed borate esters with ligand moieties were active against various fungi e.g Candia albicans and Alternaria soloni.

A composition containing one or more alkyl ammonium compounds [7] or orthoborates, metaborates and perborates of alkyl metals are good wood preservative.

\section{Experimental}

All experimental works were carried out in the lab of Department of Chemistry, Jahangirnagar University, Savar, Dhaka, Bangladesh. Solvents were dried and distilled before use. Synthesis

\subsection{Preparation of Silver Metaborate}

Standard solution of recrystallized Borax (AR, Merck, Germany) and saturated solution of silver nitrate taken in stochiometric proportions were prepared. Silver nitrate solution was than added in one portion with constant stirring to borax solution. A crude white precipitate of silver metaborate was formed. The precipitate was filtered as quickly as possible by suction under nitrogen to avoid the hydrolysis and washed with $5 \%$ solution of boric acid followed by small amount of distilled water. The precipitate was quickly dried in vacuum evaporator by heating at $60{ }^{\circ} \mathrm{C}$ to $80^{\circ} \mathrm{C}$ for $5-6$ hours. The drying process was again carried out for further 3-4 hours in high vacuum. A white powdered product obtained was $\mathrm{AgBO}_{2}$.

$\begin{array}{lllll}\mathrm{Na}_{2} \mathrm{~B}_{4} \mathrm{O}_{7}+3 \mathrm{H}_{2} \mathrm{O} & \rightarrow & 2 \mathrm{NaBO}_{2}+ & 2 \mathrm{H}_{3} \mathrm{BO}_{3} . \\ 2 \mathrm{NaBO}_{2}+2 \mathrm{AgNO} 3 & \rightarrow & \mathrm{AgBO}_{2}+ & 2 \mathrm{NaNO}_{3} . \\ \mathrm{Na}_{2} \mathrm{~B}_{4} \mathrm{O}_{7}+3 \mathrm{H}_{2} \mathrm{O}+2 \mathrm{AgNO} 3 & \rightarrow & 2 \mathrm{AgBO}_{2}+2 \mathrm{NaNO}_{3}+ & 2 \mathrm{H}_{3} \mathrm{BO}_{3} .\end{array}$

\subsection{Reaction of $\mathrm{AgBO}_{2}$ with benzoyl Chloride}

Fine suspension of $\mathrm{AgBO}_{2}(0.5 \mathrm{~g})$ in dry acetone was prepared first. The solution of $0.3857 \mathrm{ml}$ of benzoyl chloride in acetone was added dropwise from a pressure equalizing dropping funnel to $\mathrm{AgBO}_{2}$ and reflux at $60^{\circ} \mathrm{C}$ for 4 hours. The liquid supernatant was filtered and evaporated yield a light yellow mass. This mass was recrystallized from dry acetone gave a pale yellow crystalline powder $(\mathbf{2 . 2})$ which was washed first with $6 \mathrm{~N}$ $\mathrm{HNO}_{3}$ followed by distilled water and dried at $100{ }^{\circ} \mathrm{C}$ to $105^{\circ} \mathrm{C}$.

\subsection{Reaction of $\mathrm{AgBO}_{2}$ with Phthaloyl Chloride}

Fine suspension of $\mathrm{AgBO}_{2}(0.5 \mathrm{~g})$ in dry acetone was prepared first. The solution of 0.478 $\mathrm{ml}$ of phthaloyl chloride in acetone was added dropwise from a pressure equalizing dropping funnel to $\mathrm{AgBO}_{2}$ and reflux at $60^{\circ} \mathrm{C}$ for 6 hours. The liquid supernatant was filtered and evaporated yield a viscous oily white product. The final oily white product was washed with dry benzene for three times. After recrystallization from acetone gave a white leafy crystal (1.2) which was finally washed first with carbon tetrachloride. The compound is soluble in acetinitrile and acetone.

\subsection{Reaction of $\mathrm{AgBO}_{2}$ with Oxalyl Chloride}

Fine suspension of $\mathrm{AgBO}_{2}(0.5 \mathrm{~g})$ in dry $\mathrm{CH}_{2} \mathrm{Cl}_{2}$ was prepared first. This was allowed to cool at $-5^{\circ} \mathrm{C}$. The solution of $0.381 \mathrm{ml}$ of Oxalyl chloride in acetone was added dropwise from a pressure equalizing dropping funnel to $\mathrm{AgBO}_{2}$ and stir for 2 hours at $-5^{\circ} \mathrm{C}$. Then was reflux at $60^{\circ} \mathrm{C}$ for 3 hours. The liquid was filtered out and evaporated yield a viscous 
oily white product. The final oily white product was then the mass was extracted with dry acetone that after evaporation on vacuum evaporator yielded white shiny mass (1.3).

\section{Antifungal Test}

\subsection{Preparation of Media}

Sugar $4 \%$ and $7 \%$ carboxymethyl cellulose sodium were added to the distilled water with vigorous stirring. Then was heated to boil with constant stirring. Heating continue for making a clear solution. The media was than cooled at room temperature.

A moisten piece of bread was taken at Petri disc. The Petri discs were stored at humidity chamber with $95 \% \mathrm{RH}$ and $29{ }^{\mathrm{O}} \mathrm{C}$. The pencillium spores were matured in 21 days. The matured spores were spread on the controlled media as well as in the concentration series of tested compounds. The Petri discs were incubated for 21 days (for complete germination time) at $37 \pm 2{ }^{\mathrm{O}} \mathrm{C}$.

\section{Results and discussion}

He UV absorption spectrum of compound [1.1\} in chloroform of fig(3.1) gives an absorption peak at 239.50 which is responsible for k-band for benzene ring and absorption peak at 274.50 indicates the $\mathrm{CO}$ group interact in benzoyl borate. The IR (KBr) absorption at $\sim 3070 \mathrm{~cm}^{-1}$ (fig: 3.2) indicates the aromatic $\mathrm{C}-\mathrm{H}$ stretching. The absorption at $1603 \mathrm{~cm}^{-1}$ and $1158.37 \mathrm{~cm}^{-1}$ clearly indicates the presence of carbonyl group. The other peaks related to angle bending and ring stretching vibration of borate ion. The peaks are at $1128 \mathrm{~cm}^{-1}, 933(\mathrm{~s}) \mathrm{cm}^{-1}$ and $708(\mathrm{~s}) \mathrm{cm}^{-1}$.

\section{Fig: 3.1.}

Fig: 3.2.
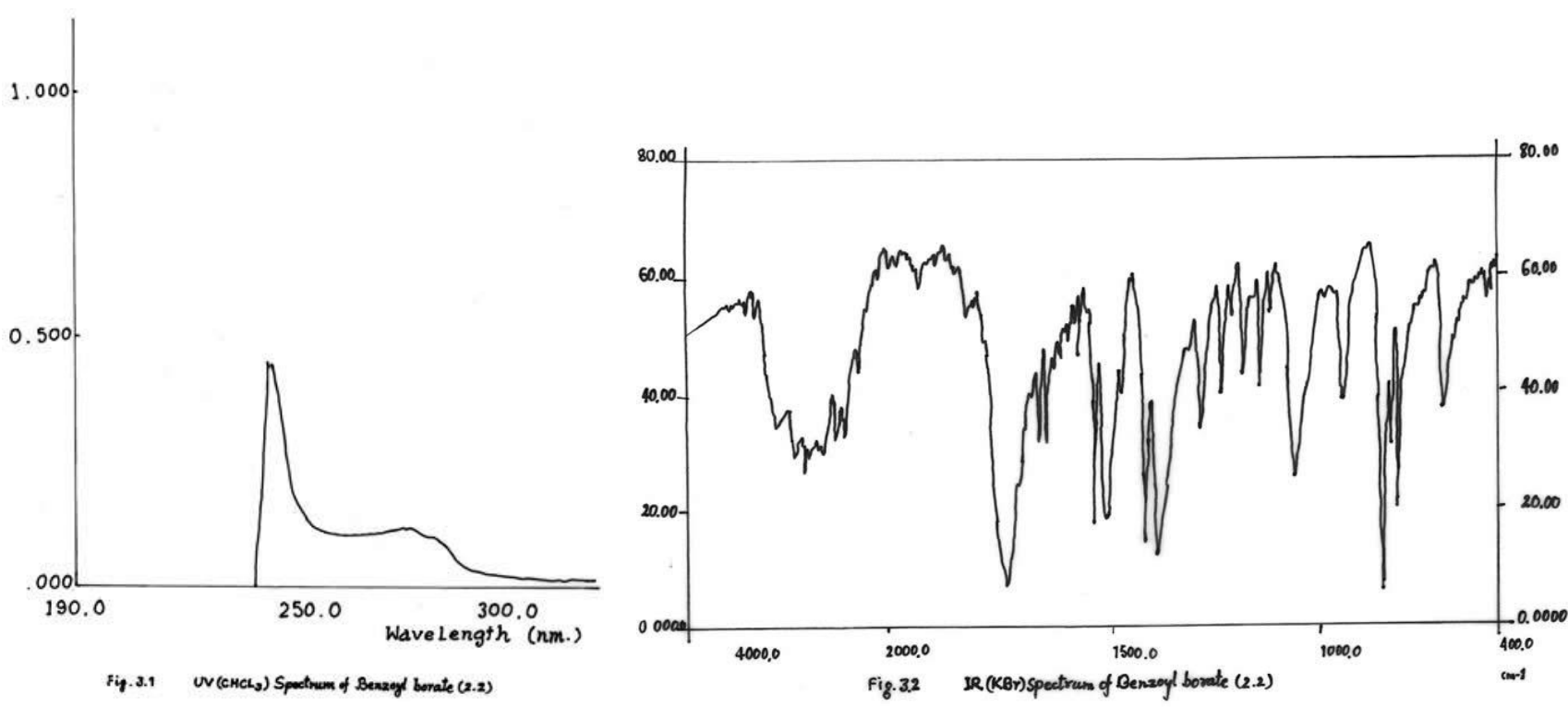


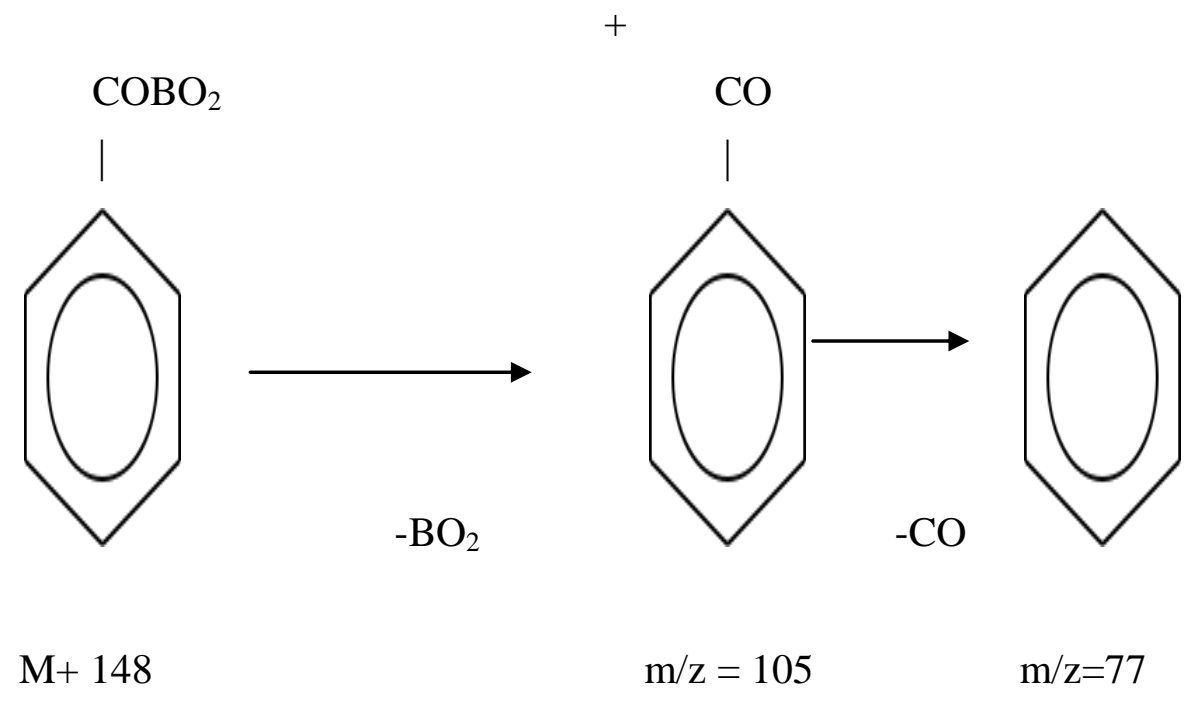

2.2

The mass spectrum (2.2) in fig 3.3 clearly shows benzoyl ion $\left(\mathrm{C}_{2} \mathrm{H}_{5} \mathrm{CO}+\right)$ at 105 , phenyl ion $\left(\mathrm{C}_{2} \mathrm{H}_{5}+\right)$ at 77 . There is a strong peak at 122 which is of benzoic acid formed by the hydrolysis of benzoyl borate. A peak at 42 is due to $\mathrm{BO}_{2}$.

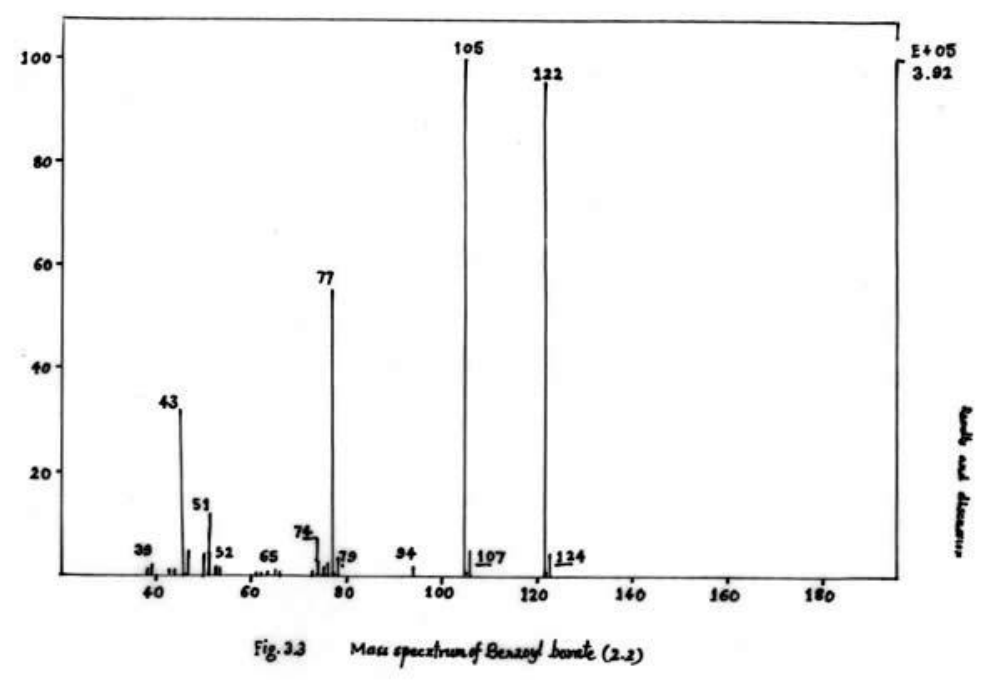

According to the spectral analysis the reaction between benzoyl chloride and silver metaborate occur as following scheme: 

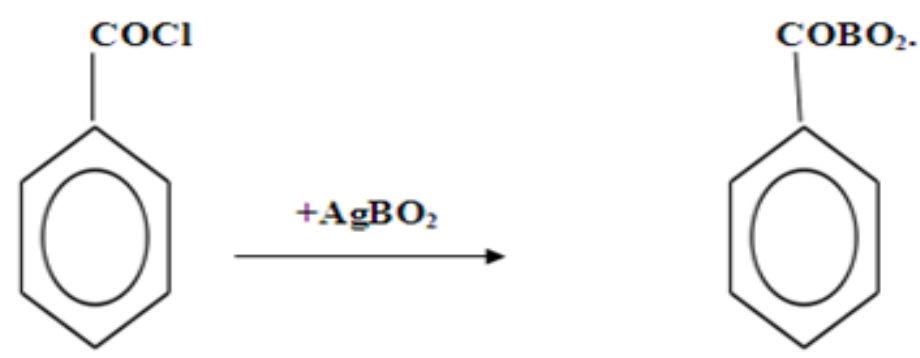

The reaction between silver metaborate and phthaloyl chloride results with the formation of phthaloyl borate.

The IR (KBr) spectrum of new compounds in (fig.3.4) shows a very strong absorption at $\sim 1697.6 \mathrm{~cm}^{-1}$ clearly indicates the presence of carbonyl group. The medium absorption at $1585 \mathrm{~cm}^{-1}, 1154 \mathrm{~cm}^{-1}$ and $1508.5 \mathrm{~cm}^{-1}$ indicates the aromatic $\mathrm{C}-\mathrm{H}$ stretching. A strong peak at $796.7(\mathrm{~s}) \mathrm{cm}^{-1}$ indicates out of plane $\mathrm{C}-\mathrm{H}$ bending vibration for orthodisubstituted benzene.

The mass spectrum [9] clearly shows benzoyl ion at 105 and phenyl at 77 . The parent molecular ion peak is at 402 . The peak at 374 and 346 are due to the loss of $\mathrm{CO}$ groups from the parent molecule. A peak at 303 is due to $\mathrm{C}_{4} \mathrm{H}_{4}(\mathrm{CO})_{2} \mathrm{~B}_{2} \mathrm{O}_{2} \mathrm{C}+6 \mathrm{H}_{2} \mathrm{BO}_{2}$ ). There is a clear peak at 43 for $\mathrm{BO}_{2}$.

Based on spectral data the reaction scheme is suggested as following:

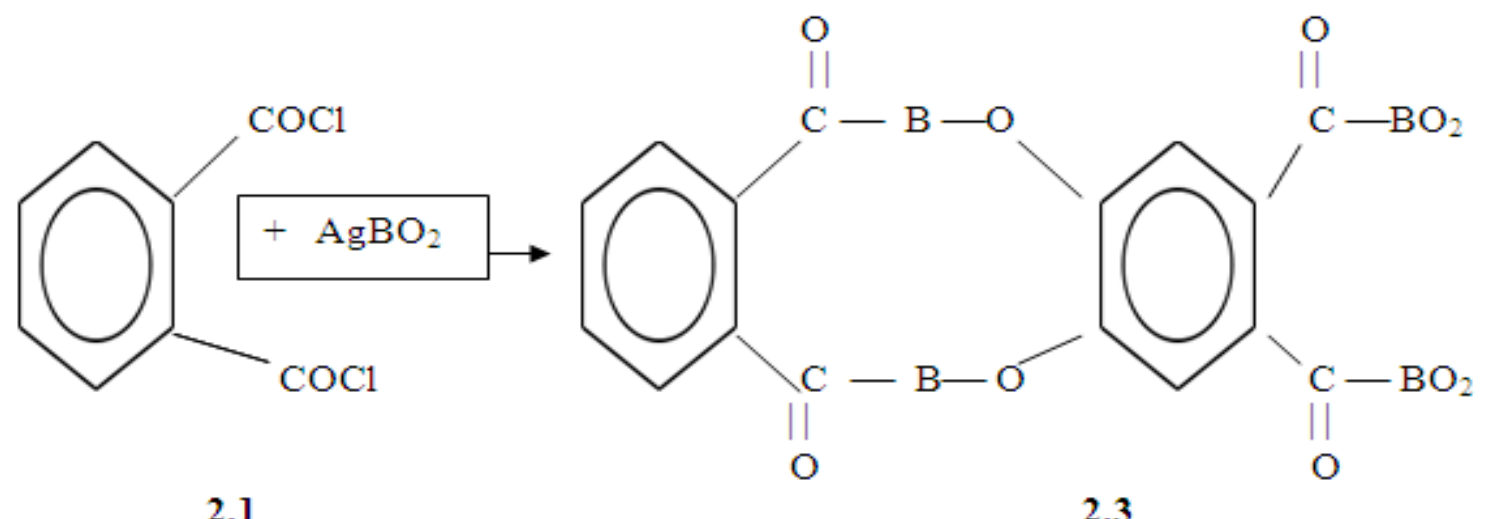

The IR (KBr) of (2.4) in (fig 3.6) shows the absorption at $3222.5(\mathrm{~s}) \mathrm{cm}^{-1}$ for $\mathrm{OH}$ stretching. The other peaks are related to angle bending and angle stretching vibration for borate ion. A strong absorption at $1194.1 \mathrm{~cm}^{-1}$ indicates in plane $\mathrm{B}-\mathrm{OH}$ and angle deformation. Another peak at $1700 \mathrm{~cm}^{-1}$ is due to $\mathrm{CO}$ stretching.

The following reaction scheme is suggested according to the spectral data. 


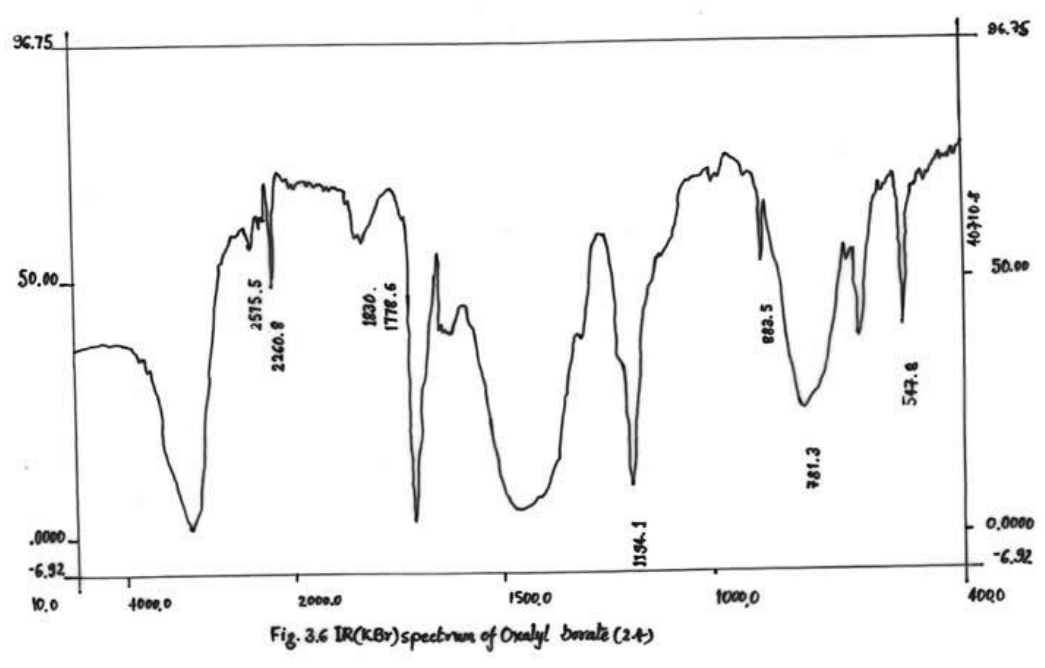

\section{$\mathrm{COCl}$}

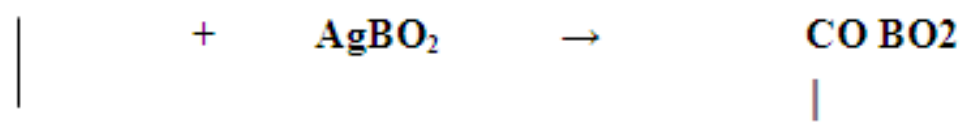

$\mathrm{COCl}$

$\mathrm{CO} \mathrm{BO} 2$

\section{Biological activity test}

\begin{tabular}{|l|l|}
\hline Compound & LD50 $(\mu \mathrm{g} / \mathrm{ml})$ \\
\hline Zineb(Control) & 77.7 \\
\hline Benzoyl Borate & 17 \\
\hline Phthaloyl Borate & 80 \\
\hline Oxyl Borate & 48 \\
\hline
\end{tabular}

The fungicidal effect increases in hydrophobicity and electron withdrawing nature of benzene ring substituents. Benzoyl borate is most effective among the series.

\section{Conclusion}

Synthesis of organoborate is difficult due to the hydrolysis of the compounds. As discuss earlier benzoyl borate particularly may be a promising fungicidal candidate for the preservation of celluloid museum materials.

\section{References}

1. Haider SZ, Safiullah S, J Natur. Sci. Math, 1968, 8(1) 35-43(eng.)

2. Dewanjee, S Safiullah, M.Sc Thesis 1966, Dhaka University.

3. Sountang N.O.V. Chem. Rev. 1953, 52,251.

4. Krogh-Moc, J of Phy. Chem, 1962, 3(2),61. 
5. Richard L.W.S African ZA 9504,684(Cl C09D) 12 July 1966 Appl 95/4684, 7 June 1995, 30 pp (Eng)

6. Laxmi B, Tandon, JP and Shina SK, Curr. Sci, 1984, 53(11), 566-9(Eng.).

7. Wolfang M Johannes, Volker S.C, Ger offer DE3, 610,374(CI B27K/52), 01 October 1987, Appl. 27 Mar. 19864 pp.

8. PhD Thesis - Studies on the Molecular modification of Titanocene Dichloride and chloroauric Acid: Brine Shrimp Lethal action and DNA Interaction of their derivatives for the search of Effective Antitumor Compounds. Jahangirnagar University, January 2000.

9. Synthesis, Characterization and Fungicidal Effects of some Organoborates -

Shaheen Akther_- a Thesis submitted for the partial Fulfilment of Master of Science in

Organic Chemistry, Department of Chemistry, Jahangir Nagar University, Savar Dhaka Bangladesh. 